\title{
Qualidade da Energia Elétrica em Sistemas de Automação
}

\section{Quality of electrical energy in automation systems}

\author{
José Maurício dos Santos Pinheiro ${ }^{1}$
}

\begin{abstract}
Palavras-chave:
\section{Resumo}

Automação

As redes de automação atuais resultam em sistemas de gerenciamento comple-xos, compostos por inúmeros protocolos, diversos meios para o

Disponibilidade transporte da in-formação e novas tecnologias de sinais. O seu projeto deve incorporar dispositi-vos de alimentação, proteção e sistemas de

Condicionamento aterramento elétrico capazes de ga-rantir a integridade dos ativos de rede contra falhas no sistema elétrico. Assim, a escolha de materiais de quali-

Infraestrutura dade e uma infraestrutura bem executada são quesi-tos importantes para o bom funcionamento de toda a rede.
\end{abstract}

\begin{abstract}
The current automation nets result in systems of complex administration, com-posed by countless protocols, several means to the information transport and new signs technologies. Its project should incorporate feeding devices, protection and electrical grounding systems capable to guarantee the integrity of the net assets against flaws in the electric system. This way the choice of good quality materials and an infrastructure well executed are important requirements to the good opera-tion of the whole net.
\end{abstract}

Key words:

Automation

Availability

Conditioning

Infrastructure

1 Professor Especialista - Curso Tecnológico de Redes de Computadores - UniFOA 


\section{Introdução}

Sistemas de automação são aplicações que necessitam de energia elétrica com alta disponibilidade e livre de distúrbios, ou seja, contar com um fornecimento de energia elétrica confiável é um desafio por se tratar de sistemas os quais necessitam de alimentação de qualidade para maximizar sua eficiência e o seu tempo de funcionamento.

Um dos requisitos mais críticos em redes de automação é a proteção da inte-gridade da informação quando esta trafega através de um meio sujeito a distúr-bios no fornecimento da energia elétrica. Nesse aspecto, blindagem e aterramen-to elétrico são itens mandatários para garantir a integridade dos dados. Segundo Pinheiro (2008), "as ameaças mais comuns para os equipamentos eletrônicos são os ruídos elétricos, variações e transientes de tensão, interrupções no forne-cimento, entre outros." Seguindo este raciocínio, Aldabó (2001) preconiza que "as soluções para os distúrbios na energia elétrica podem ser compreendidas e apli-cadas em três níveis distintos: aterramento apropriado, proteções e sistema al-ternativo de fornecimento." Ou seja, através do planejamento da infraestrutura elétrica, associado com um projeto que inclua sistemas de aterramento elétrico e dispositivos de proteção, é possível eliminar ou pelo menos minimizar bastante as consequências que os distúrbios de energia elétrica podem causar a uma rede de automação.

Neste sentido é inquestionável a necessidade de um sistema que forneça e-nergia elétrica de qualidade e confiabilidade e, através dele, espera-se obter uma rede com imunidade suficiente para operar sem degradação na presença de dis-túrbios eletromagnéticos.

\section{Qualidade da Energia Elétrica}

O conceito de qualidade da energia elétrica está relacionado ao conjunto de alterações que podem ocorrer no sistema elétrico e que podem ser representadas por qualquer problema de energia manifestado nos valores de tensão, corrente ou nas variações de frequência, que resulte em falha ou má operação de equi-pamentos. Tais alterações podem ocorrer em várias partes do sistema elétrico, seja nas instalações dos usuários ou no próprio sistema da concessionária de eletricidade.

Segundo Aldabó (2001), "O conceito de qualidade de energia elétrica significa a busca por desenvolvimento de meios para erradicar ou minimizar os problemas em dispositivos alimentados por fontes de energia."

A qualidade da energia elétrica fornecida é relevante para aplicações críticas em todas as condições operacionais. Entretanto, ainda segundo Aldabó (2001), "a energia elétrica comercial pode, ocasionalmente, ser fornecida com instabili-dades, oscilação, surtos e transientes além dos limites operacionais dos siste-mas." Isso se deve a alterações na demanda da transmissão de energia elétrica, afetada por falhas de projeto ou por novas necessidades de conversão dos consumidores na rede elétrica. A realidade é que os problemas na qualidade da energia elétrica vêm se a-gravando em todo o mundo por diversas razões, entre elas duas se destacam:

- Instalação de cargas não lineares - uso de equipamentos que aumen-tam os níveis de distorções e podem levar o sistema a condições de insta-bilidade durante o fornecimento da energia elétrica;

- Maior sensibilidade - os equipamentos eletrônicos estão cada vez mais sensíveis aos efeitos dos distúrbios oriundos de fontes de alimentação elétrica. É cada vez mais comum a utilização de dispositivos de automação nos ambientes industriais, comerciais e residenciais.

Além dos problemas ocasionais no fornecimento de energia elétrica (quedas de tensão, apagões, entre outros), a ocorrência dos impulsos elétricos de alta in-tensidade e de curta duração, normalmente provenientes das descargas atmosféricas, é extremamente prejudicial a todo tipo de equipamento eletrônico usado nesses ambientes. Isso ocorre porque os equipamentos eletrônicos são cada vez mais sensíveis a problemas de qualidade de energia e mais poluidores também, provocando distúrbios que podem afetar outros equipamentos próximos. Segundo Sanches (2003), "a interferência eletromagnética provoca a aceleração da degeneração dos circuitos integrados devido aos transientes e surtos de tensões e correntes provocados no equipamento influenciado." 


\subsection{Fontes de Interferência}

O ambiente eletromagnético de um sistema de automação pode ser encarado como o resultado do funcionamento dos diversos elementos adicionados ao ruí-do ambiente no qual estão inseridos e pode ser definido pelos seus diversos equipamentos e sistemas constituintes, tais como a rede elétrica, tipo de edifica-ção, infraestrutura, tipo de cabeamento, equipamentos instalados e pelo ambiente externo que o circunda. Conforme Pinheiro (2008), "o ambiente eletromagnético pode ser alterado à medida que ocorrerem reformulações no layout dos equipamentos, do cabeamento e, principalmente, na instalação elétri-ca."

\subsection{Interferência Eletromagnética}

A Interferência Eletromagnética ou EMI (Electromagnetic Interference) pode ser de- finida como a interferência ou ruído gerado nos sistemas eletroeletrônicos como resultado das características inerentes aos dispositivos instalados nesses sistemas. Sanches (2003), esclarece que "o nome genérico dado a toda energia eletromagnética, que cause resposta indesejável (ruído elétrico), sem considerar o ruído inerente ao próprio componente... é Interferência Eletromagnética...".

A EMI constitui-se num obstáculo à melhoria dos níveis de confiabilidade dos equipamentos utilizados nos sistemas de automação, afetando diretamente seus usuários e vem se tornando uma das maiores causas de falhas nas trans-missões de dados, imagens, monitoração remota etc.

Na figura 1 são apresentados dois exemplos típicos de EMI que se propaga através da rede de energia elétrica ou por meio de ondas de rádio. As duas for-mas interferem no funcionamento do equipamento eletroeletrônico (aparelho de TV).

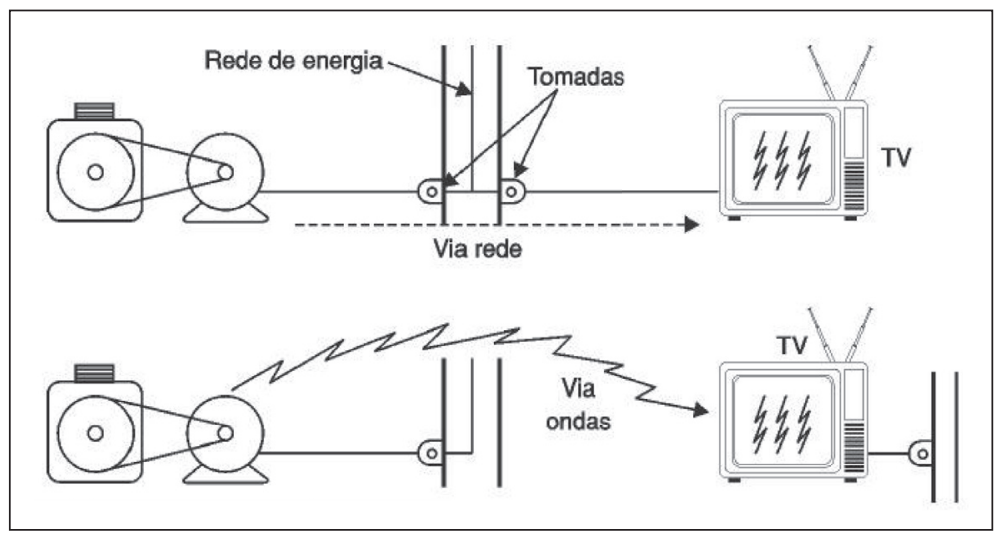

Figura 1 - Exemplos de EMI através da rede elétrica e sinais de rádio

Essa forma de interferência é um dos maiores causadores de falhas em redes de comunicação, principalmente quando são utilizados protetores, cabos e acessórios inadequados para o sistema de energia elétrica. Ela pode ocorrer in-ternamente ou externamente ao sistema de comunicação, mas sua causa sempre se origina nas perturbações eletromagnéticas.

Para se eliminar problemas de interferência eletromagnética, todas as questões relativas à infraestrutura da rede devem ser levantadas durante o proje-to com vistas à melhor solução. Por exemplo, o cabeamento metálico é um dos principais responsáveis pela conexão física entre os diversos dispositivos e a-cessórios que compõem uma rede de automação. Algumas providências básicas podem ser tomadas para evitar que o ruído elétrico afete o funcionamento dos equipamentos a partir do cabeamento. Dentre os métodos de redução de ruídos destacam-se o balanceamento dos níveis de tensão nas extremidades dos cabos, a blindagem das estruturas por onde passa a rede de cabos de automação e, principalmente, o cuidado com a conexão dos cabos e o aterramento elétrico. Segundo Pinheiro (2003), "é importante observar que os conectores representam as ligações mais fracas de um sistema de cabeamento." Pinheiro (2003) ressalta ainda que "as características e a eficiência do aterramento devem satisfazer às prescrições de segurança pessoais e funcionais da instalação." 
2.2.1 Efeitos da Interferência Eletromagnética

Todos os equipamentos eletrônicos propagam a corrente elétrica e, con-sequentemente, produzem um campo eletromagnético. Esse campo eletromagnético é composto por duas entidades: um campo elétrico presente quando há tensão elétrica e um campo magnético, que existe quando há fluxo de corrente elétrica. Ambos os campos determinam o tipo de interferência eletromagnética que estarão presentes no sistema, como mostra a Figura 2.

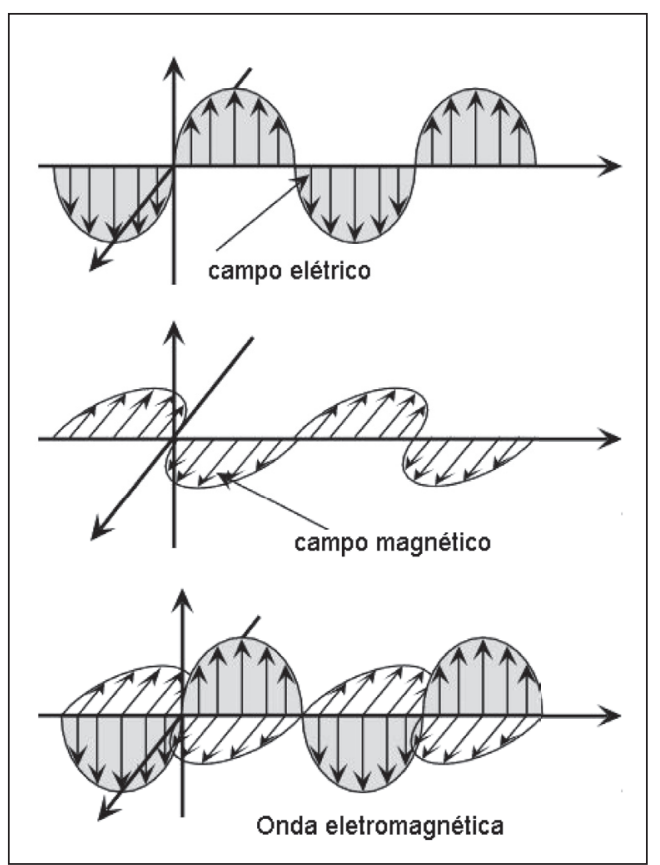

Figura 2 - Interação entre o campo elétrico e o magnético

A EMI pode ser responsável por diversos problemas, dentre eles podemos ter falhas na comunicação entre os dispositivos da rede, caracteres estranhos nas interfaces de vídeo, alarmes acionados sem motivo aparente, falhas esporá-dicas e que não seguem uma lógica, queima de circuitos eletrônicos e ruídos elétricos gerados nas fontes de alimentação.

Segundo Kouyoumdjian (1998), “as perturbações eletromagnéticas são devidas a fenômenos de diferentes tipos." Na verdade, todo circuito eletrônico produz algum tipo de campo magnético ao seu redor e, assim, se torna gerador de EMI. Como consequência, temos a transferência energia eletromagnética (ou acoplamento) entre um equipamento "fonte" e um equipamento "vítima", que pode ocorrer por radiação ou condução, ou ambos. Em todos os casos temos o envolvimento de uma fonte de energia eletromagnética, um dispositivo que responde a esta energia (vítima) e um caminho de transmissão (acoplamento) que permite a energia fluir da fonte até a vítima, conforme mostrado na Figura 3.

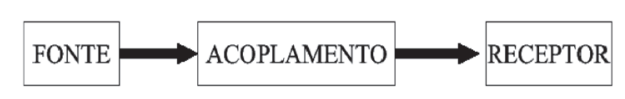

Figura 3 - Transferência entre fonte e receptor

Para diagnosticar um problema de EMI, o modelo fonte - acoplamento - re-ceptor pode se bastante útil. Como mencionado, são necessários os três compo-nentes, simultaneamente, para existir um problema de EMI:

- Uma fonte de energia;

- Um receptor, que possa ser perturbado por essa energia;

- Um acoplamento (ou caminho) para transferir esta energia indesejável en-tre a fonte e o receptor.

Inicialmente, deve-se identificar a fonte de perturbação eletromagnética, o mecanismo de acoplamento (como que as perturbações eletromagnéticas gera-das são acopladas ao circuito) e a vítima (o circuito que está sendo afetado). En-tão é possível estudar uma solução para o problema trabalhando-se em um ou mais destes componentes para se reduzir o ruído acoplado. $\mathrm{Na}$ Figura 4, temos exemplos típicos desses três componentes. Observa-se ainda que existem diver-sas combinações possíveis entre eles, mas nem todas resultam em um problema de EMI. 


\begin{tabular}{|c|c|c|}
\hline $\begin{array}{l}\text { FONTES } \\
\text { - microprocessadores } \\
\text { - fontes chaveadas } \\
\text {-ESD } \\
\text { - transmissores } \\
\text { - geradores de RF } \\
\text { - distúrbios no } \\
\text { fornecimento de energia } \\
\text { - descargas atmosféricas }\end{array}$ & $\begin{array}{l}\text { CAMINHOS } \\
\text { IRRADIADOS: } \\
\text { - campos } \\
\text { eletromagnéticos } \\
\text { - crosstalk (diafonia) } \\
\text { CoNDUZIDOS: } \\
\text { - sinal digital } \\
\text { - entrada de energia } \\
\text { - aterramento }\end{array}$ & $\begin{array}{l}\text { RECEPTORES } \\
\text { - digitais } \\
\text { - reset } \\
\text { - outras lógicas } \\
\text { - analógicos com } \\
\text { baixa potência } \\
\text { - receptores de RF }\end{array}$ \\
\hline
\end{tabular}

Figura 4 - Modelo Fonte - Acoplamento (caminho) - Receptor

O problema da EMI pode ser solucionado através da intervenção num dos componentes do modelo: na fonte, no caminho ou no receptor, ocorrendo basi-camente de três formas:

- $\quad$ Supressão da emissão de EMI na fonte;

- O caminho de acoplamento deve ser o mais ineficiente possível;

- Tornando o receptor menos susceptível ao ruído elétrico.

\subsubsection{Prevenção contra EMI}

Uma instalação elétrica adequada é essencial para que os equipamentos não sejam afetados por EMI. É necessário manter os terminais de conexão dos componentes curtos para minimizar indutâncias. O mesmo vale para conexões de filtros, blindagens e dispositivos de isolação para o potencial de terra. Outra preocupação, conforme Negrisoli (2004), “todas as partes metálicas de uma instalação que não tenham por finalidade a condução de corrente elétrica, devem ser aterradas de modo a garantir segurança a pessoas que se utilizam dessa instalação".

Uma providência importante é instalar protetores de transientes e filtros no ponto de entrada dos equipamentos para minimizar a poluição das conexões in-ternas. Quando se usam tanto protetores de transientes quanto filtros, é preciso instalar os protetores mais próximos da entrada de energia para proteger os filtros e outros dispositivos internos. Pode ser necessário combinar mais de um método de proteção, dependendo dos problemas que se quer prevenir ou solucionar e, assim, oferecer diversos níveis de proteção.
Dois conceitos básicos devem ser considerados: em primeiro lugar devem-se tratar todos os cabos como se fossem antenas não intencionais. Qualquer condutor com dimensão maior que $1 / 20$ de comprimento de onda pode se com-portar como uma boa antena para essa onda. Considerar também que um cabo, mesmo blindado, poderá irradiar EMI. É muito comum que uma corrente de alta frequência seja acoplada na blindagem, fazendo com que a blindagem do cabo se comporte como uma antena.

Em segundo lugar devem-se determinar os circuitos mais críticos para atu-arem como transmissores não intencionais, por exemplo, circuitos que operam com sinais altamente repetitivos como o sinal de sincronismo. No caso dos cabos e conectores de rede, quanto mais alta a frequência de operação, maior deve ser a qualidade desses componentes. Cabos atuam como antenas não intencionais (tanto receptoras como transmissoras) para energia de RF. Conectores propiciam fuga não intencional de (e para) a blindagem do cabo e maus conectores podem tornar um ótimo cabo, ineficiente. Dessa forma, cabos e conectores devem ser considerados como um sistema e não individualmente.

Uma analogia interessante é uma mangueira de jardim. A conexão da mangueira à torneira e também entre a mangueira e a conexão, são tão importantes como o material da mangueira. A melhor mangueira do mundo vaza se a conexão não for boa. $\mathrm{O}$ mesmo acontece com cabos e conectores para pro-blemas de EMI. Seguem-se algumas recomendações:

- Blindagem - Utilizar blindagem de qualidade para frequências de opera-ção até $10 \mathrm{MHz}$. Acima desta frequência, fugas 
tendem a ocorrer através da blindagem. Nesse caso, devem-se utilizar malhas de alta cobertura, ou malhas sobre folhas metálicas. Somente folhas metálicas poderiam ser utilizadas, mas uma ruptura poderia provocar fugas, portanto, malhas sobre folhas são preferíveis;

- Conectorização - Usar conectores de qualidade para qualquer frequência de operação, particularmente acima de 10 MHz. O objetivo é prover cober-tura de $360^{\circ}$ na junção entre a blindagem do cabo e o chassi do equipa-mento. Cada junção não deve oferecer fugas (blindagem do cabo ao co-nector, conector a conector, e conector ao chassi);

- Filtros - Não sendo possível utilizar blindagem, devem-se filtrar os sinais no cabo. A filtragem é necessária para evitar que frequências mais altas entrem ou saiam do sistema através dos cabos. Pequenos filtros de alta frequência compostos de ferrites e de capacitores de bypass funcionam bem. Manter os terminais destes componentes curtos e capacitores de by-pass conectados ao potencial terra do chassi e não ao potencial terra do circuito (a menos que estes dois terras sejam comuns). Os filtros devem ser instalados próximos dos conectores para minimizar a captação do ruí-do pelos circuitos internos do equipamento;

- Encaminhamento de cabos - Cabos internos ao equipamento também são antenas não intencionais. Deve-se tomar cuidado com a rota desses cabos, evitando que passem perto de ranhuras no chassi (por exemplo, ranhuras de ventilação). Isso é especialmente crítico quando tais cabos transportam sinais analógicos de baixo nível de potência;

- Aterramento de condutores - Ao utilizar flat cables, utilizar o maior núme-ro de fios possível para retornos de terra e os espalhe uniformemente no cabo. Isso minimiza áreas de loop que funcionam como antenas. A melhor condição é uma linha de retorno de terra para cada sinal.

\section{Condicionamento e Fornecimento Autônomo de Energia}

Sistemas de automação são aplicações que necessitam de energia elétrica com alta disponibilidade e livre de distúrbios. No atendimento desses sistemas, na complementação ou substituição da eletricidade fornecida pela concessionária de energia, podemos contar com fontes de energia elétrica de reserva, capazes de suprir a demanda de uma rede de comunicação com total confiabilidade.

\subsection{Condicionamento de Energia}

Condicionar energia significa estabelecer padrões de comportamento (conti-nuidade no fornecimento, limites especificados, isenção de distúrbios) previsíveis para que a energia fornecida pelo sistema público de distribuição seja utilizada pelos consumidores de forma eficiente e sem riscos de acidentes pessoais e materiais.

Um dispositivo para condicionamento de energia recebe a eletricidade forne-cida pela concessionária (normalmente carregada de distúrbios e eventos poten-cialmente destrutivos e imprevisíveis) e a transforma em energia condicionada com um comportamento previsível e aceitável para a maioria das cargas que dela dependem.

O condicionamento da energia para um sistema de automação pode ser con-seguido pela utilização de quatro tipos básicos de dispositivos:

- UPS: Quando existe queda ou interrupção da rede elétrica, a energia é suprida por um conjunto de baterias, que através de circuitos específicos, converte a energia da forma contínua para alternada;

- Estabilizadores de tensão: mantém a tensão fornecida aos equipamentos dentro dos limites especificados, indicados como um valor percentual da tensão de operação (tensão nominal);

- Filtros: Filtram os ruídos de alta frequência proveniente da rede elétrica como as interferências de radiofrequência (RFI) e eletromagnéticas (EMI); 
- Protetores de surto: Dispositivos destinados a suprimir tensões perigosas da rede elétrica (proteção contra surtos de tensão e sobrecarga, tensões induzidas por descargas atmosféricas, contatos acidentais de linhas elétri-cas de diferentes potenciais, indução etc.).

\subsection{Equipamentos Sensíveis}

Equipamentos sensíveis são definidos como aqueles que têm seu desempe-nho mais amplamente afetado pelos distúrbios da rede elétrica. Dentre eles po-demos citar os equipamentos comumente encontrados nas redes de comunica-ção (computadores, impressoras, modems, roteadores, switches, hubs etc.), e-quipamentos de áudio e vídeo, equipamentos médico-hospitalares e de teleco-municações, entre outros. Motores elétricos, lâmpadas e eletrodomésticos em ge-ral costumam apresentar menor sensibilidade aos distúrbios mais comuns da re-de elétrica e, portanto, não são considerados equipamentos sensíveis. Conforme assinala Kouyoumdjian (1998), “impõe-se, portanto, o conhecimento das medidas que permitam a coabitação pacífica entre produtos sensíveis, de um lado, e produtos emissores de interferências, de outro."

Igualmente, independente da sensibilidade dos equipamentos, torna-se importante a escolha correta dos dispositivos de proteção (fusíveis e disjuntores), de tal modo que, na ocorrência de um defeito na instalação elétrica, a menor parte dela seja desligada. Negrisoli (2004) salienta que "a proteção mais próxima do defeito deve atuar primeiro".

Os dispositivos para condicionamento de energia visam corrigir um ou mais desvios no fornecimento da eletricidade para as cargas e podem ser divididos em três categorias básicas:

- Dispositivos que filtram ou regulam o fornecimento de energia da conces-sionária:

$\square$ Transformadores isoladores;

$\square$ Dispositivos para proteção contra surtos;

$\square$ Reguladores de tensão;

$\checkmark$ Condicionadores de linha;

$\square$ Filtros harmônicos.
- Equipamentos que regeneram a energia fornecida pela concessionária de energia ou geram a sua própria energia:

$\square$ Grupo Motor-Gerador (GMG)

- Dispositivos de alimentação ininterrupta de energia:

$\square$ Uninterruptible Power Supply (UPS)

Os dispositivos para condicionamento de energia fazem parte de um grupo de equipamentos usados em sistemas de fornecimento de energia elétrica. Figueira (2005) esclarece que "sistema de energia é um termo genérico que especifica um grupo de equipamentos eletromecânicos e eletroeletrônicos que tem como objetivo a geração, a conservação e a transformação da energia elétrica."

\subsection{Criticidade do Sistema Elétrico para Automação}

O nível de criticidade do sistema elétrico de uma rede de automação pode ser determinado através da análise das necessidades dos equipamentos constituin-tes dessa rede, da infraestrutura existente e da qualidade da energia elétrica for-necida. Pode-se classificar esse nível de criticidade do sistema elétrico em:

- Alta: quando os equipamentos necessitam de $100 \%$ de confiabilidade e disponibilidade de energia em função da importância de sua continuidade de funcionamento;

- Média: quando os equipamentos necessitam de $100 \%$ de confiabilidade de qualidade de energia condicionada, porém, pode ser interrompido, desde que seja de uma forma programada. Isto é, numa situação de ausência de energia CA de entrada, o dispositivo de fornecimento e condicionamento de energia deve ter autonomia suficiente para manter os sistemas em funcionamento por um tempo mínimo para o seu desligamento programado;

- Baixa: quando os equipamentos necessitam apenas de confiabilidade na qualidade de energia condicionada, porém não sofrem e nem geram prejuízos com as interrupções prolongadas de energia. Este é um 
caso típico de equipamento sensível como sistemas de iluminação ambiente, onde as variações da má qualidade de energia, tais como, micro interrupções, transitórios e oscilações da energia ou mesmo nas situações de falta de energia prolongadas, simplesmente se desliga sem danos ou prejuízos ao sistema.

\subsection{Sistemas de Missão Crítica}

A evolução da tecnologia e a integração entre as redes de automação e as redes corporativas criaram um novo desafio no projeto das instalações elétricas para os sistemas de comunicação: o aumento de cargas sensíveis e aplicações de missão crítica. Todo e qualquer equipamento que necessite de proteção con-tra distúrbios da rede elétrica é considerado uma carga sensível.

Já a expressão "aplicações de missão critica" faz referência aos sistemas que necessitam estar disponíveis 24 horas por dia durante os 365 dias do ano, siste-mas de automação, por exemplo. Esse tipo de sistema necessita de uma infraes-trutura adequada que propicie a disponibilidade necessária para atender as necessidades constantes dos equipamentos, com energia elétrica segura e de qua-lidade.

Outros sistemas de missão crítica devem ser igualmente protegidos e necessi-tam de formas de alimentação alternativas. Como permitir ou restringir o acesso de pessoas às instalações e setores da empresa se os sistemas de controle de acesso físico estão sem alimentação elétrica?

Trancas com códigos, leitoras de cartões inteligentes, Etiquetas RFID, dispo-sitivos biométricos, CLP's etc., são todos dependentes de energia elétrica. Siste-mas de captação e gravação de imagens (câmaras e gravadores de vídeo) devem estar sempre alimentados, bem como detectores de movimento e presença. Sistemas de comunicação, como enlaces de rádio e centrais telefônicas também devem possuir redundância de fontes de alimentação elétrica.

Quanto mais críticos e importantes forem os sistemas, maior será a exigência de redundância e segurança da infraestrutura da rede de suporte. Assim, há a necessidade de redundância de equipamentos de mesma função para garantir o suprimento de energia das cargas criticas e, nesses casos, devem ser usa- dos sistemas de energia ininterrupta do tipo UPS e Grupo Motor-Gerador (GMG), além de rede elétrica adequada.

A inspeção é outro quesito essencial nas instalações elétricas e deve ser rea-lizada mesmo que voluntariamente. $O$ ponto que garante a harmonia de todo o projeto é a manutenção, que aumenta a vida útil da instalação e reduz os riscos. Essa manutenção deve seguir alguns procedimentos padrão, estabelecidos de acordo com norma ABNT NBR 5410 e deve ser realizada com uma periodicidade definida.

A norma ABNT NBR 5410 cobre os diversos tipos de instalações elétricas de baixa tensão como edificações residenciais, comerciais e industriais em geral, sendo aplicável também no projeto elétrico das redes de automação.

\section{Gerenciamento de Energia}

O termo "gerenciamento de energia" ou Power Management é usado em di-versos contextos. Os mais comuns são em referência ao controle de consumo de energia elétrica e ao monitoramento de equipamentos para condicionamento e fornecimento ininterrupto de energia, como mostra a Figura 5.

A instalação desses equipamentos cria um ambiente protegido dos distúrbios no fornecimento de energia elétrica, mas isso é feito com um propósito maior: preservar os dados que trafegam na rede e que são utilizados pelos diversos sis-temas. Para que isso seja possível, no entanto, é preciso que os equipamentos sejam constantemente monitorados e que, em caso de alterações no fornecimento de energia, os sistemas implicados sejam adequadamente desligados antes que o corte de energia efetivamente aconteça.

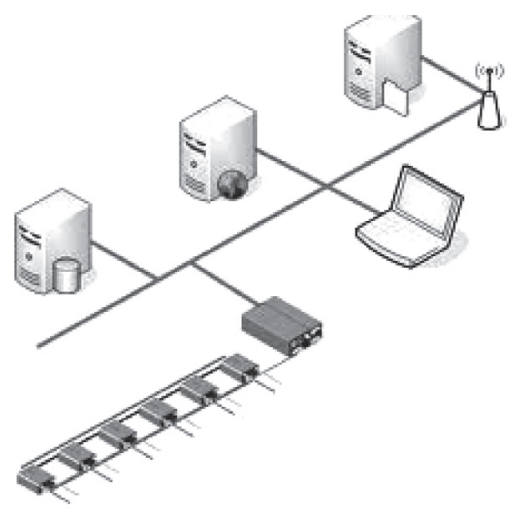

Figura 5 - Conceito de Gerenciamento de Energia 


\subsection{Sistemas Remotos de Gerenciamento}

Uma boa parte dos novos equipamentos utilizados nos projetos de sistemas de automação possui algum tipo de recurso de gerenciamento de energia que permite colocálo em algum estado de consumo reduzido. Outros equipamentos eletrônicos como impressoras, copiadoras etc., também possuem modos de baixo consumo ou espera. De qualquer maneira, depende do usuário configurar o que se chama de políticas de consumo, diretrizes que definem os limites de tempo utilizado para assumir quando o equipamento está ocioso e qual o estado de consumo em que ele deve ser colocado.

Entretanto, a necessidade de intervenção do usuário para a configuração e habilitação desses mecanismos de controle pode se tornar um empecilho ao ge-renciamento de energia nos ambientes industriais, onde o número de equipamentos em rede é consideravelmente grande. Nesse tipo de estrutura é pouco produtivo configurar cada equipamento individualmente. Além disso, pode ser necessário estabelecer diferentes políticas de consumo para diferentes períodos do dia ou mesmo optar-se por não habilitar o gerenciamento de energia para evitar acidentes durante procedimentos não programados em que determinados equipamentos (servidores de rede e controladores lógicos, por exemplo), precisam estar acessíveis na rede.

Uma forma para contornar esses problemas é centralizar as operações que normalmente seriam executadas em cada máquina através de um sistema remoto de gerenciamento. Desse modo, não só o administrador do sistema teria condições de configurar políticas de consumo para todos os equipamentos a partir de um ponto único, como poderia fazê-lo de maneira a não interferir com o andamento de outros processos na planta.

Outro aspecto no qual a economia de energia pode desempenhar um papel importante é o de redes cujos equipamentos são alimentados através de UPS. Neste caso, pode ser extremamente útil estender o tempo de "sobrevida" propor-cionado pelas baterias do UPS. O propósito de estender esse tempo de autono-mia das baterias é permitir o desligamento correto e ordenado dos equi- pamentos da rede em caso de falha prolongada no fornecimento de energia. Entretanto, para que esse processo seja eficiente, além de um elemento central capaz de monitorar as condições do fornecimento da energia e acionar remotamente o desligamento dos equipamentos ou sua entrada em modos de baixo consumo, também é necessário um sistema elétrico corretamente dimensionado e confiável.

Alguns requisitos mínimos devem ser observados para correta instalação dos equipamentos. Devem ser considerados os seguintes aspectos:

- Ambiente físico - área reservada para os equipamentos, distâncias de pa-redes para ventilação, temperatura de operação, umidade relativa, presen-ça de partículas na atmosfera, área de manutenção;

- Dispositivos de proteção - devem ser dimensionados os condutores de entrada e saída, bem como os respectivos dispositivos de proteção nos quadros de energia com seus graus de seletividade corretamente dimensi-onados;

- Cabeamento elétrico - os cabos de energia devem ser conectados com terminais adequados e protegidos através de canaletas de acordo com as normas vigentes em relação às cores e seções mínimas para a redução das perdas de tensão;

- Aterramento elétrico - o aterramento deve apresentar boas condições de conexão, com resistência ôhmica baixa, e principalmente deve ser execu-tada a equalização de potenciais, ou seja, a interligação de todos os con-dutores terra a um barramento comum, a fim de evitar diferenças de poten-cial nas diversas áreas de trabalho;

- Documentação e Identificação - uma documentação atualizada é fun-damental para a adequação das cargas e futuras manutenções ou expan-sões da planta. A identificação dos quadros e numeração dos circuitos au-xilia na rápida detecção de defeito no caso de emergências. 
As instalações elétricas para uso em sistemas de automação devem ser proje-tadas para suportar uma infinidade de equipamentos que, além de funcionarem de formas bem diferentes, exigem um fornecimento de energia constante e de qualidade. Os prejuízos relativos ao consumo de energia fora de condições ideais de fornecimento não se limitam aos gastos não orçados com a manutenção da infraestrutura elétrica em si. É essencial conhecer detalhadamente a estrutura do sistema elétrico que serve às redes de automação e, a partir desta informação, mapear as possíveis causas dos problemas elétricos e se prevenir contra eles através de políticas de manutenção adequadas.

\section{Referências Bibliográficas}

1. ABNTNBR 5410 - Instalações Elétricas de Baixa Tensão. Rio de Janeiro: Associação Brasileira de Normas Técnicas, 2005.

2. ALDABÓ, Ricardo. Qualidade na Energia Elétrica. São Paulo: Artliber Editora 2001.

3. FIGUEIRA, Antonio E. Sistemas NoBreak Estáticos. Rio de Janeiro: Antenna Edições Técnicas, 2005.

4. KOUYOUMDJIAN,Ara.ACompatibilidade Eletromagnética. São Paulo: Artliber Editora, 1998.

5. NEGRISOLI, Manuel E.M. Instalações Elétricas: Projetos Prediais. 3 ed. São Paulo: Edgard Blucher, 2004.

6. PINHEIRO, J. M. S. Guia Completo de Cabeamento de Redes. Rio de Janeiro: Editora Campus, 2005.

7. PINHEIRO, J. M. S. InfraEstrutura Elétrica para Redes de Computadores. Rio de Janeiro: Editora Ciência Moderna, 2008.

8. SANCHES, Durval. Interferência Eletromagnética. Rio de Janeiro: Editora Interciência, 2003.

\section{Endereço para Correspondência:}

José Maurício dos Santos Pinheiro jm.pinheiro@uol.com.br

Curso Tecnológico de Redes de Computadores Centro Universitário de Volta Redonda Campus Três Poços

Av. Paulo Erlei Alves Abrantes, $n^{\circ} 1325$, Três Poços - Volta Redonda / RJ CEP: 27240-560 